\title{
Polar mesosphere summer echo strength in relation to solar variability and geomagnetic activity during 1997-2009
}

\author{
M. Smirnova, E. Belova, and S. Kirkwood \\ Swedish Institute of Space Physics, Kiruna, Sweden \\ Received: 9 November 2010 - Revised: 24 February 2011 - Accepted: 28 February 2011 - Published: 16 March 2011
}

\begin{abstract}
This paper is based on measurements of Polar Mesosphere Summer Echoes (PMSE) with the $52 \mathrm{MHz}$ radar ESRAD, located near Kiruna, in Northern Sweden, during the summers of 1997-2009. Here, a new independent calibration method allowing estimation of possible changes in antenna feed losses and transmitter output is described and implemented for accurate calculation of year-to-year variations of PMSE strength (expressed in absolute units - radar volume reflectivity $\eta$ ). The method is based on radar-radiosonde comparisons in the upper troposphere/lower stratosphere region simultaneously with PMSE observations. Inter-annual variations of PMSE volume reflectivity are found to be strongly positively correlated with the local geomagnetic K-index, both when averaged over all times of the day, and when considering 3-h UT intervals separately. Increased electron density due to energetic particle precipitation from the magnetosphere is suggested as one of the possible reasons for such a correlation. Enhanced ionospheric electric field may be another reason but this requires further study. Multi-regression analysis of inter-annual variations of PMSE $\eta$ shows also an anti-correlation with solar $10.7 \mathrm{~cm}$ flux and the absence of any statistically significant trend in PMSE strength over the interval considered (13-years). Variations related to solar flux and K-index account for $86 \%$ of the year-to-year variations in radar volume reflectivity.
\end{abstract}

Keywords. Meteorology and atmospheric dynamics (Middle atmosphere dynamics) - Radio science (Instruments and techniques)

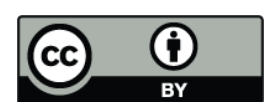

Correspondence to: $\mathrm{M}$. Smirnova (maria@irf.se)

\section{Introduction}

Since the 1980s it has been known that extremely strong radar echoes can be detected from altitudes of $80-90 \mathrm{~km}$, in high latitude regions, during summer. These echoes are known as Polar Mesosphere Summer Echoes (PMSE) and they are closely related to the visible phenomenon known as noctilucent clouds (NLC). A recent review of PMSE can be found in Rapp and Lübken (2004). While visible NLC indicate the presence of ice particles with sizes of several tens of nm (Hervig et al., 2001; Gumbel et al., 2001) formed at extremely low summer mesopause temperatures $(\sim 130 \mathrm{~K})$, PMSE occur due to scattering from fluctuations in electron density caused by a combination of electrically charged ice particles, including those of smaller sizes, and atmospheric turbulence. Thus PMSE have a dual nature: they are related both to ionospheric plasma and to the neutral atmosphere, in particular the thermal and dynamical state of the mesosphere.

Since NLC are sensitive to temperature and water vapour concentration (e.g. Lübken et al., 2007), it has been proposed that they might serve as an indicator of the values of these parameters in the mesosphere and be useful for detection of possible composition changes due to changing climate (Thomas and Olivero, 2001). Thus possible long-term trends in NLC derived using both ground-based and satelliteborne measurements attract great interest and discussion in the literature (e.g. DeLand et al., 2003, 2007; Kirkwood et al., 2008; Shettle et al., 2009).

PMSE are readily measured by VHF radars and have been monitored on a continuous basis since the 1990s. Therefore PMSE can also be used for long-term variability studies (e.g. Bremer et al., 2009; Smirnova et al., 2010). PMSE observations with radars have advantages over ground-based visual and lidar observations of NLC because they are weather and observer independent, and can be made $24 \mathrm{~h}$ a day. Satellite measurements of NLC are free from weather effects but have to be corrected for differences in observation times (DeLand

Published by Copernicus Publications on behalf of the European Geosciences Union. 
et al., 2007), and there is still some uncertainty in these corrections. However, when analysing secular variations and trends in PMSE one should bear in mind their dual nature, which means they are influenced not only by the characteristics of ice particles (NLC) but also by variations in the ionospheric plasma, which are caused by solar and geomagnetic variability. There is, for example, a clear positive correlation between the index of geomagnetic activity and PMSE occurrence rate (Bremer et al., 2006).

So far, long-term changes of PMSE were considered only in terms of occurrence rate OR (e.g. Bremer et al., 2006, 2009; Smirnova et al., 2010). In some studies a PMSE detection threshold is set for signal-to-noise ratio (SNR), in others a threshold value for the radar volume reflectivity $\eta$ is used. However, even the use of the same threshold in terms of SNR, for radars with different noise levels, implies different signals, i.e. PMSE strengths. Therefore, OR calculated according to this procedure is not suitable for comparative studies of PMSE. Unlike SNR, the radar volume reflectivity is an intrinsic characteristics of PMSE strength which can be used for comparison of PMSE measured with different radars at different locations. An additional advantage of using $\eta$ is in the fact that its value should be directly related to physical parameters such as electron and ice particle density, static stability and turbulence characteristics (Kirkwood et al., 2010b; Varney et al., 2010). Nowadays estimations of PMSE reflectivity have been made using a number of MesosphereStratosphere-Troposphere (MST) radars located both in the northern and southern polar regions (e.g. Kirkwood et al., 2007; Latteck et al., 2007, 2008; Swarnalingam et al., 2009). Comparisons between sites are dependent on the use of accurate calibration methods. So far, slightly different methods of radar calibrations have been applied at different sites which lead to uncertainly in the accuracy of cross-comparisons.

This paper is based on observations of PMSE during 1997-2009 using the MST radar ESRAD located near Kiruna in Northern Sweden. ESRAD has been running continuously since 1997 and has measured PMSE every summer using the same experimental parameters. Here we introduce a new method of independent calibration which allows accurate comparison of radar sensitivity from year to year for the ESRAD radar and can in principle be used for improving the accuracy of comparisons between sites. By using this unique PMSE data set, together with the new method of calibration, we can accurately calculate year-to-year variation of PMSE strengths (expressed in absolute units - radar volume reflectivity) over an interval exceeding one solar cycle. An important advantage of this study is that the measurements of PMSE were carried out with the same radar at the same place. This makes the data set from ESRAD more attractive for long-term study than other observations.

The goal of this paper is (1) to accurately calculate the inter-annual variations of radar volume reflectivity for PMSE over Kiruna, Sweden; (2) to quantify the contributions of solar and geomagnetic activity to those variations and (3) to test for any secular trend in PMSE strength. We start with a description of the radar and the new method for independent calibration. Then yearly averaged radar volume reflectivities for PMSE are calculated with correction according to the calibration. Finally, the relationships between year-to-year variations of PMSE $\eta$, solar $10.7 \mathrm{~cm}$ flux and local geomagnetic $\mathrm{K}$-index are evaluated.

\section{PMSE strength over summers 1997-2009}

\subsection{Radar and experiment description}

PMSE have been observed with the ESRAD MST radar, located near Kiruna, Sweden $\left(67.88^{\circ} \mathrm{N}, 21.10^{\circ} \mathrm{E}\right)$, during each summer 1997-2009, although observations from 1999 are not included here because of a radar malfunction.

ESRAD operates at a frequency of $52 \mathrm{MHz}$. The transmitter has 72 solid-state modules each of $1 \mathrm{~kW}$, thus the resulting peak power reaches $72 \mathrm{~kW}$ with a maximum duty cycle of 5\%. The pulse repetition frequency can vary from $100 \mathrm{~Hz}$ to $16 \mathrm{kHz}$ and the pulse lengths from $1-50 \mu \mathrm{s}$. The radar is able to use both Barker and complementary codes for pulse coding of the transmitted signals. The sampling interval of the receiving system can be between $1 \mu$ s and $20 \mu$ s. The radar provides information on the dynamic state of the atmosphere such as winds, waves, turbulence and layering, from the troposphere up to the lower stratosphere (ca. $1 \mathrm{~km}-$ $20 \mathrm{~km}$ altitude) and at higher altitudes when strong scatterers are present (e.g. PMSE). A detailed descriptions for ESRAD radar is given by Chilson et al. (1999), updated by Kirkwood et al. (2007).

Initially the ESRAD antenna consisted of $12 \times 12$ phased array of 5-element Yagis spaced at $4.04 \mathrm{~m}$ (0.7 times the radar wavelength) from each other. In April 2004 an extended antenna array (constant phase) with $16 \times 18$ Yagis was taken into use. The array is divided into 6 sub-arrays, each connected to separate receivers, to detect backscattered power from the atmosphere. During the PMSE measurements used here, ESRAD ran an operating mode "fca_4500" which provides an 8-bit complementary code, $600 \mathrm{~m}$ resolution, pulse train and a narrow receiver bandwidth, resulting in high sensitivity. The parameters of this experiment are presented in Table 1.

\subsection{Calculation of radar volume reflectivity}

Radar volume reflectivity $\eta$ can be calculated according to the formula (e.g. Gage, 1990):

$\eta=\frac{P_{\mathrm{r}}}{P_{\mathrm{t}}} \frac{64(2 \ln 2) r^{2}}{\pi L A_{\mathrm{e}} V_{\mathrm{f}} \Delta r}$

where $P_{\mathrm{t}}$ is power delivered to the radar, $P_{\mathrm{r}}$ is power received by the radar, $r$ is the distance to the scattering volume, $\Delta r$ is the range resolution along the radar beam, $L$ is the antenna feed loss, $V_{\mathrm{f}}$ is the fraction of the scattering volume which 
is filled with scatterers ( $V_{\mathrm{f}}=1$ was assumed) and $A_{\mathrm{e}}$ is the effective area of the receiving antenna. The power received by the radar has been determined as described in Smirnova et al. (2010) using scaling against the daily variation of galactic radio noise. For computation of $\eta$ from Eq. (1), profiles of received power with 2-min time resolution in the $80-90 \mathrm{~km}$ height range were used. Volume reflectivity was averaged over $1 \mathrm{~h}$ and its maximum over the given altitude range was taken. Values of $L=1, P_{\mathrm{t}}=72 \times 10^{3} \mathrm{~W}, A_{\mathrm{e}}=1870 \mathrm{~m}^{2}$ were used, while $A_{\mathrm{e}}$ was changed to $3740 \mathrm{~m}^{2}$ after April 2004 .

\subsection{Independent calibration}

The antenna loss figure is the most uncertain parameter in calculating the reflectivity. For a new radar, one might expect a loss figure as good as 0.8 (note that $L$ in our case is the one-way loss on transmission as any additional loss on reception is taken into account by the scaling of the detected signal against galactic noise). The value of $L$ for ESRAD was estimated to be 0.39 in August 2006 (Kirkwood et al., 2007). Antenna maintenance work has been done on several occasions since 1997, particularly in 2004 when the radar antenna array was expanded, and in 2008 when major maintenance was undertaken. Thus we expect that $L$ did vary significantly from year to year. $P_{\mathrm{t}}$ may also vary, but since $L$ and $P_{\mathrm{t}}$ appear as a product in Eq. (1), we can account for any small fluctuations in $P_{\mathrm{t}}$ by considering only apparent changes in $L$. There are also a few occasions when there are major dropouts in $P_{\mathrm{t}}$, when whole transmitter blocks fail. Each block consists of $12 \mathrm{~kW}$ power and feeds a separate 1/6th of the antenna array, so such dropouts also affect $A_{\mathrm{e}}$ (for transmission). In order to correctly estimate $\eta$, allowing for major dropouts in $P_{\mathrm{t}}$ and possible changes in $L$, we use the result found by Kirkwood et al. (2010a) concerning radar-radiosonde comparisons in the upper troposphere/lower stratosphere (UTLS) region. For the UTLS region, Kirkwood et al. (2010a) showed that Fresnel scatter, as quantified by the normalised power reflection coefficient $\rho^{2} / \Delta r$, is proportional to $M^{2}$, where $M$ is the dry term of mean vertical gradient of generalized potential refractive index. The same constant of proportionality was found to apply for $50 \mathrm{MHz}$ radars with very different poweraperture products and in very different locations (ESRAD, the MARA radar in Antarctica and the Indian MST radar at Gadanki). $M$ can be determined from radiosonde measurements according to the formula:

$M=-77.6 \times 10^{-6} \frac{P}{T} \frac{\partial \ln \theta}{\partial z}$,

where $P$ is pressure in $\mathrm{hPa}, T$ is temperature, $\theta$ is potential temperature, both in $K$.

For any particular radar (e.g. Kirkwood et al., 2010a):

$$
\frac{|\rho|^{2}}{\Delta r}=\frac{4 \pi \lambda^{2} V_{\mathrm{f}}}{64(2 \ln 2) A_{\mathrm{e}}} \eta
$$

Table 1. Parameters of ESRAD experiment used in this study.

\begin{tabular}{ll}
\hline Radar modes & fca_4500 \\
\hline Pulse length $(3 \mathrm{~dB})$ & $\begin{array}{l}2.1 \mu \mathrm{s}(8 \mathrm{bit} \text { complementary } \\
\text { code } \\
\text { with nominal } 4 \mu \mathrm{s} \text { baud })\end{array}$ \\
& $600 \mathrm{~m}$ \\
Sampling resolution & $128(98.4 \mathrm{~ms})$ per code up \\
Coherent integrations & to 2004 \\
& $32(24.6 \mathrm{~ms})$ per code \\
Filter bandwidth & $250 \mathrm{kHz}$ \\
Pulse repetition frequency & $1300 \mathrm{~Hz}$ \\
Duty cycle & $2.7 \%$ \\
Start altitude & $4.8 \mathrm{~km}$ \\
End altitude & $105 \mathrm{~km}$ \\
Receiver filter efficiency $C_{\text {filt }}$ & 0.72 \\
Mean altitudes for $\left(S_{\text {sys }}+S_{\text {sky }}\right)$ & $30-50 \mathrm{~km}$ \\
Galactic noise $T_{\text {sky }}$ & $1680-4500 \mathrm{~K}$ \\
\hline
\end{tabular}

where $\eta$ is calculated using Eq. (1). Hence $\rho^{2} / \Delta r$ is proportional to $\eta / A_{\mathrm{e}}$ and we can conclude that $\eta / A_{\mathrm{e}}$ must also be proportional to $M^{2}$, i.e.

$\eta=B \cdot A_{\mathrm{e}} M^{2}$,

where $B$ is a constant of proportionality.

First we compute nominal values of volume reflectivity $\eta_{\text {nom }}$ for all heights (covering both UTLS and PMSE echoes) by applying Eq. (1) with $L=L_{\text {nom }}=1$. We then find corresponding median values of $B_{\text {nom }}$ for each year from Eq. (4) by comparing $\eta_{\text {nom }}$ with $M^{2}$ determined from radiosondes.

For calculations of $M^{2}$, we used data from regular radiosondes launched twice per day in Bodø, Norway, $250 \mathrm{~km}$ SW from ESRAD. Radiosondes were launched at 12:00 UT and 24:00 UT, and we used 1-h averaged ESRAD data for the same times. For each ESRAD and radiosonde data set, corresponding to either 12:00 UT or 24:00 UT, we calculated a linear fit of $\eta_{\text {nom }} / A_{\mathrm{e}}$ from ESRAD to $M^{2}$ derived from the radiosondes, for the altitude range from $8.1 \mathrm{~km}$ to $13.5 \mathrm{~km}$, together with the correlation between them. We kept regression coefficients $B$ only when this correlation was statistically significant at the $95 \%$ level (for the vast majority of such cases the correlation was higher than 0.5). For these cases, we can assume that the sonde samples the same synoptic air mass as ESRAD. By examining the day-to-day variation of the regression coefficients $B$, including all months of the year, we first identified periods affected by major dropouts in $P_{\mathrm{t}}$ (these affected parts of the PMSE seasons in 2006 and 2007). We then recalculated $\eta_{\text {nom }} / A_{\mathrm{e}}$ taking account of these dropouts and recomputed the corresponding $B$.

Scatter plots of $\eta_{\text {nom }}$ against $M^{2}$ for June-July data sets for each year are presented in Fig. 1. Note that the scale is logarithmic on both axes. The red lines indicate the radar sensitivity threshold for gradient of potential refractive index 

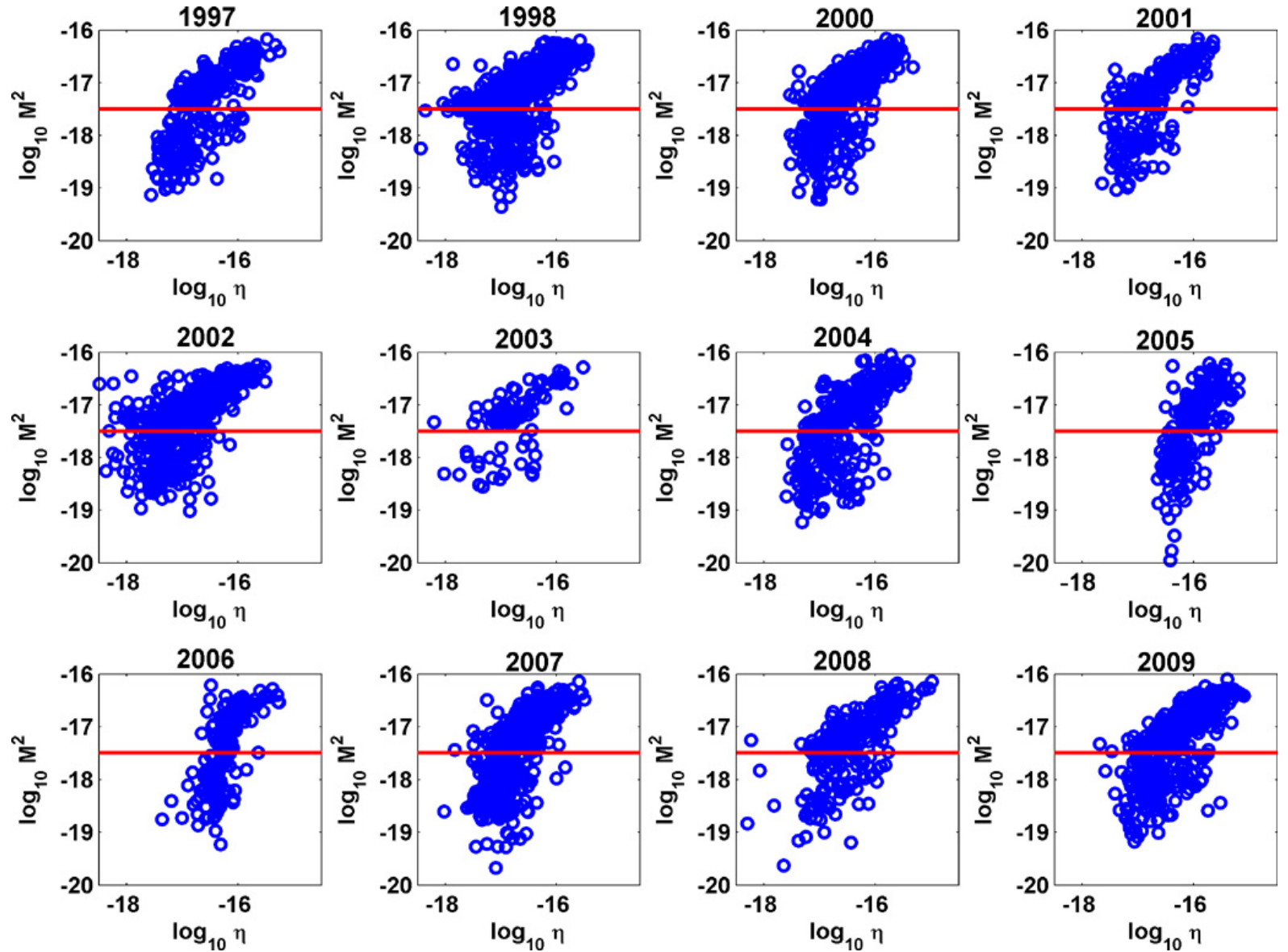

Fig. 1. Scatter plots of the logarithm of the squared refractive index gradient, $M^{2}$ derived from radiosonde data against logarithm of radar volume reflectivities, $\eta$ for altitude range from $8.1 \mathrm{~km}$ to $13.5 \mathrm{~km}$, for the months of June and July.

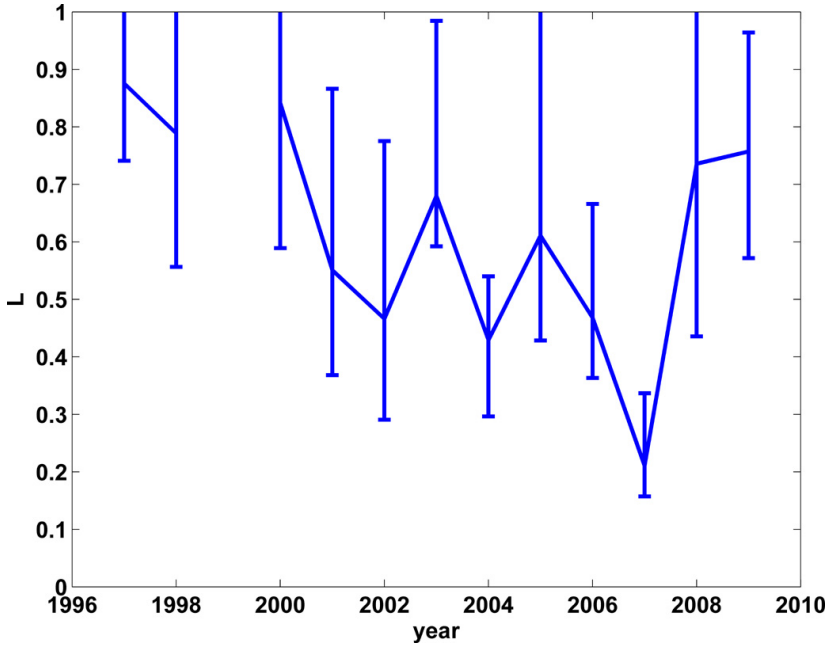

Fig. 2. Variations of effective losses in the antenna feed together with their quartiles for 1997-2009. (i.e. the level below which there is no correlation). One can see that, for every year, data above the red line lies compactly and with small spread indicating a good correlation between $\eta_{\text {nom }}$ and $M^{2}$. Below the red line where $M^{2}$ is relatively small (less than $10^{-17.5}$ ), there is no useful radar signal, only noise.

The value of $L=0.39$ evaluated for 2006 is the best available (Kirkwood et al., 2007). It was estimated by comparison of PMSE volume reflectivities between ESRAD and a new, collocated, well calibrated MARA (Movable Atmospheric Radar for Antarctica) radar. However, the loss figure was calculated assuming $P_{\mathrm{t}}=72 \mathrm{~kW}$. Since our comparison with radiosondes has identified a dropout in $P_{\mathrm{t}}$ at the time the comparison was made, a more correct estimate would be $L(2006)=0.47$. Since the average value of $B$ has been found to be essentially the same in a wide variety of conditions, even at completely different locations over the globe (Kirkwood et al., 2010b), it seems reasonable to assume that it does not vary from year to year at the same location. Thus we can find the appropriate value of $L$ for each year as

$L($ year $)=B_{\text {nom }}(2006) / B_{\text {nom }} \cdot L(2006)$ 

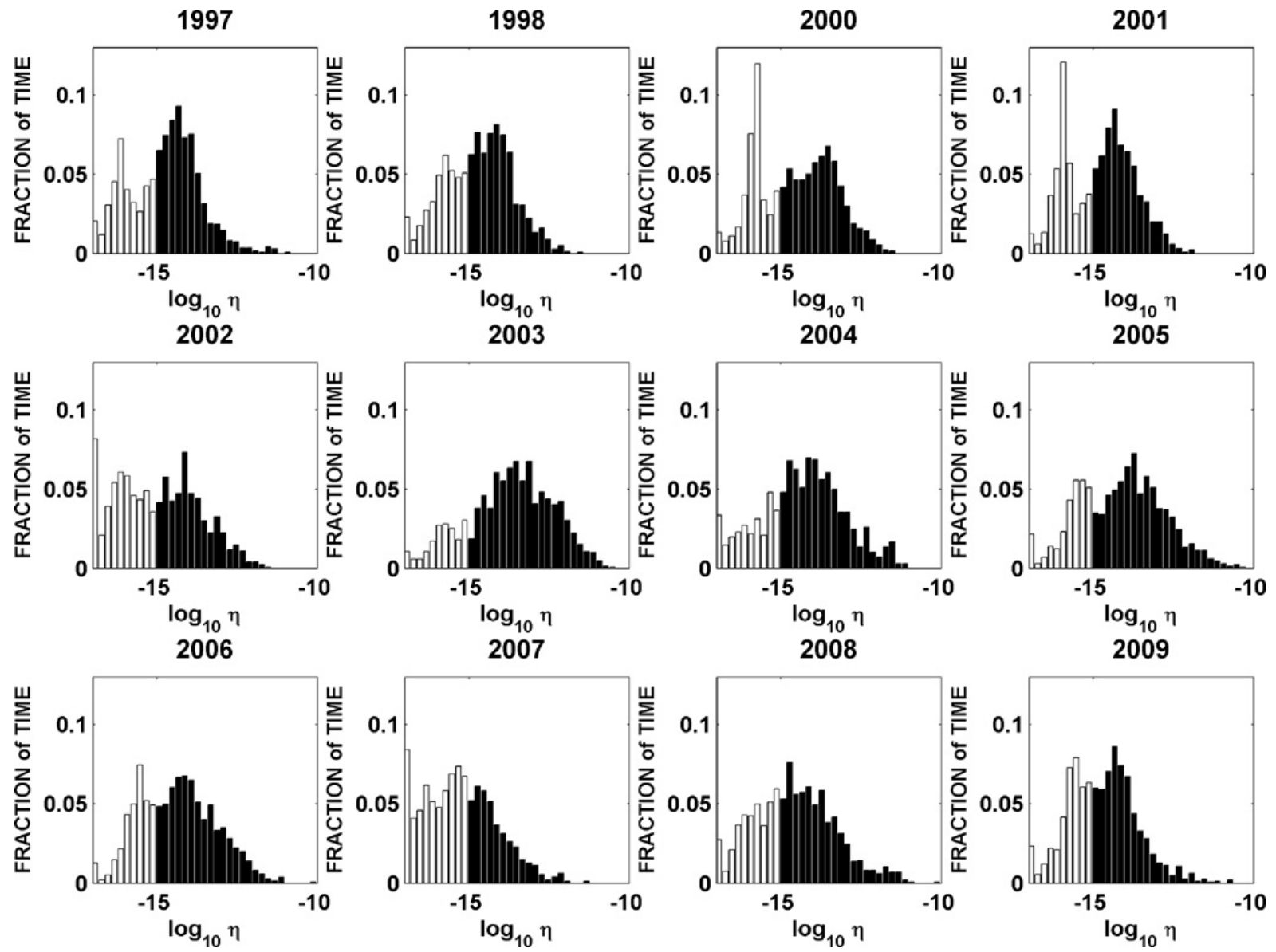

Fig. 3. The distributions of logarithm of ESRAD volume reflectivity for different years. The histograms refer to maximum $\eta$ over altitudes $80-90 \mathrm{~km}$ for one hour averages. White and black bars correspond to noise and PMSE, respectively.

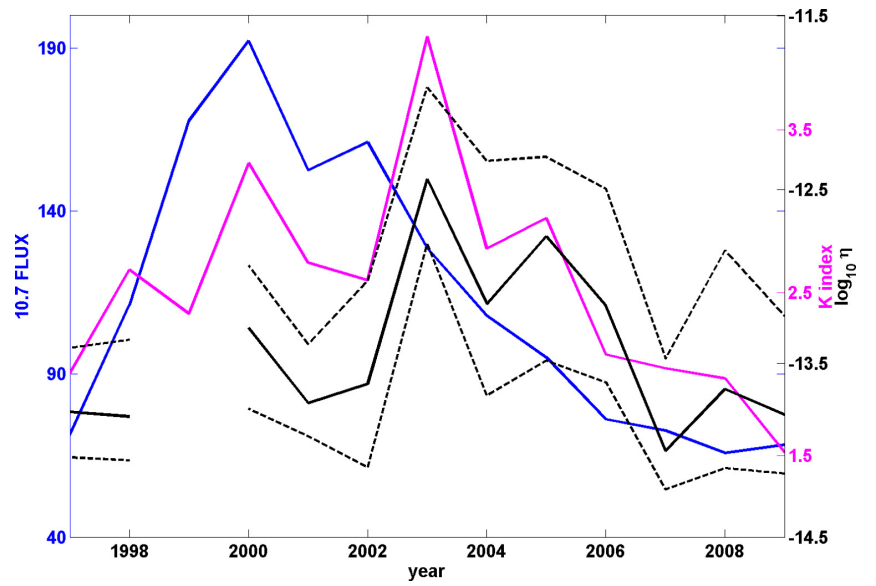

Fig. 4. Year-to year variations of $\log _{10}$ PMSE volume reflectivities (black solid line) together with their quartiles (grey dashed lines), $\mathrm{K}$-index (magenta line) and solar flux (blue line). with $L(2006)=0.47$,

where $B_{\text {nom }}$ are average values over the two summer months, June and July, for each year. The resultant values of $L$ are shown in Fig. 2. From this figure it is clear that $L$ has had high values close to $0.8-0.9$ in the first few years of operation (up to year 2000) and from 2008 onwards. Between summer 2000 and 2001 the initial stages of work to extend the antenna array to twice the area were started and some reduction in $L$ is noticeable. The full enlarged antenna was connected to the system in April 2004, leading to further degradation in $L$, which subsequently varied from year to year as minor maintenance was carried out. Finally, following major maintenance in 2008, $L$ returned to a relatively high value.

For the PMSE, we can correct our $\eta_{\text {nom }}$ for the variation of $L$

$\eta($ year $)=\eta_{\text {nom }} / L($ year $)$

For future comparison with results from other radars it can be noted that, for the UTLS echoes, the corresponding average value of $\left(\rho^{2} / \Delta r\right) / M^{2}=1.1 \times 10^{-3}$. 


\section{Results}

\subsection{Distributions of volume reflectivity strengths}

We have calculated the loss-corrected maximum ESRAD volume reflectivities over the altitude range $80-90 \mathrm{~km}$, with $1 \mathrm{~h}$ averaging, for the interval from 1 June to 31 July for each year. The histogram of PMSE reflectivity strengths is presented in Fig. 3. PMSE signals were defined to correspond to reflectivities exceeding the threshold value of $10^{-15} \mathrm{~m}^{-1}$ and are shown by black bars. For consistency we have used the same threshold as used for calculation of PMSE OR in Smirnova et al. (2010). This value is well above the background noise (white bars).

In general the distributions for each year are a superposition of two populations, PMSE and noise. The location of the maximum in the volume reflectivity distribution varies from $2 \times 10^{-15}$ to $3 \times 10^{-14} \mathrm{~m}^{-1}$. In 2002 and even more so in 2007, the most probable PMSE strength was very low, close to the chosen threshold. (It can also be noted that the distributions of PMSE strength are far from Gaussian so that mean values are of limited use.)

\subsection{Variation of volume reflectivity over 1997-2009 and its relation to solar and geomagnetic activity}

Bremer et al. (2006, 2009) have shown that year-to-year variations of PMSE OR are to a large extent correlated with geomagnetic and solar activity. Smirnova et al. (2010) have also found a significant positive correlation between PMSE OR and geomagnetic activity. We have tested this hypothesis for PMSE volume reflectivity. A proxy of solar activity is the $10.7 \mathrm{~cm}$ radio flux, while the $\mathrm{K}$-index represents the local geomagnetic activity during 3-h intervals. We use local $\mathrm{K}$-index rather then planetary k- or a-index because we want to study the relationship between $\eta$ and geomagnetic activity at the same location during different times of the day.

We calculated seasonally averaged PMSE volume reflectivities according to the following procedure. Firstly, we calculated the daily means of loss-corrected ESRAD volume reflectivities averaged over $1 \mathrm{~h}$ and exceeding the chosen threshold of $10^{-15} \mathrm{~m}^{-1}$. And then we took a median over the time interval from 1 June to 31 July. Mean values for the same time interval for $10.7 \mathrm{~cm}$ solar flux and daily averaged K-index were also calculated. In Fig. 4 the behaviours of all three quantities over the years 1997-2009 are presented. One can easily notice that radar $\eta$ changes closely follow those in K-index at least until 2006. However, any solar cycle signature in $\eta$ is, if present, not very pronounced. In order to quantify the relation between these three parameters, and allow for a possible long-term trend, we have calculated the multi-parameter linear regression as follows:

$$
\begin{aligned}
\eta= & A_{0}+A_{1} \times(\text { year }-1997)+A_{2} \times\left(F-F_{\text {mean }}\right) \\
& +A_{3} \times\left(K-K_{\text {mean }}\right)
\end{aligned}
$$

where $\eta$ are the seasonal medians of daily mean volume reflectivities for PMSE, $F$ and $K$ are the seasonal mean solar $10.7 \mathrm{~cm}$ flux and K-indexes of geomagnetic activity, respectively. $F_{\text {mean }}$ and $K_{\text {mean }}$ are their mean values for 1997-2009.

Additionally, we computed mean values of volume reflectivity for PMSE for every three hours and then averaged them over the time interval from 1 June to 31 July for each year. We calculated the same fit as in Eq. (7) but for inter-annual variations for each 3-h interval (K-index values are also available separately for each 3-h interval but local noon values of solar flux had to be used.) For fitting we used the MATLAB "stepwise" function allowing finding the best fit by interactively moving predictors in and out of the fit in accordance with their statistical significance. The method begins with an initial model having no terms and holds a few steps. At each step the level of significance for F-statistic (p-values) is computed to test models with and without a potential term. We test p-values for all possible combinations of terms and retain those terms which give p-values less than 0.05 .

The results of the final fits are presented in Table 2. It shows that the year-to-year variation of PMSE $\eta$ and geomagnetic index are positively correlated throughout the entire day. The correlation between PMSE $\eta$ and solar flux is always negative and significant for the interval 00:0009:00 UT. For daily mean data the radar volume reflectivity is statistically significantly correlated with solar flux (negatively) and with magnetic index (positively). The only significant positive trends in the seasonal median behaviour of $\eta$ are found for the interval from 09:00 to 12:00 UT. There is no trend for daily mean data. Table 2 also presents the coefficients of determination $\left(R^{2}\right)$ which, for a linear regression, are equal to the square of the correlation coefficient between observed and modelled (linear fit) data values. $R^{2}$ determines the proportion of variability in $\eta$ that is accounted for by two predictors: F10.7 cm solar flux and K-index. We see that, for example, for daily averaged data $86 \%$ of the year-to-year variation of PMSE volume reflectivity can be explained by solar and geomagnetic activity.

It is instructive to compare these results, based on PMSE volume reflectivities, to previously published results based on PMSE occurrence rate. For example, Smirnova et al. (2010) analysed OR using measurements from 19972008, also from ESRAD. While the range of year-to-year variations in $\eta$ is more than an order of magnitude, the range in OR is only $\pm 15 \%$. So $\eta$ should be a more sensitive indicator of year-to-year changes. It is notable that the signs of the correlations between OR and magnetic activity (positive) and solar flux (negative) were found to be the same as now found for $\eta$, but the statistical certainty of the result is much higher using $\eta$ than OR (the p-value of the final fit was 0.11 for OR, and 0.0001 for $\eta$ ). Bremer et al. (2009) used measurements from 1994-2008, made by radars located $\sim 200 \mathrm{~km}$ northwest of ESRAD. They found a similar range in OR as at ESRAD, a similar positive correlation with magnetic activity, but also a positive correlation with solar activity. However 
Table 2. The coefficients of multi-parameter regression for year-to-year variation of PMSE $\eta$ together with their $95 \%$ confidence intervals and p-values of F-statistics for testing hypothesis of a zero coefficient. $P$ is the p-value of F-statistic for testing the hypothesis of all zero coefficients and $R^{2}$ is the square of the correlation coefficient between original $\eta$ and the final fit. The parentheses indicate that coefficient was set to zero in the final fit.

\begin{tabular}{ccccccc}
\hline UT (h) & $A_{0}\left(10^{-14}\right)$ & $A_{1}\left(10^{-15}\right)$ & $A_{2}\left(10^{-16}\right)$ & $A_{3}\left(10^{-13}\right)$ & $P$ & $R^{2}$ \\
\hline 00:00-03:00 & 4.9 & $(4.1)$ & $-12.5 \pm 9.1$ & $8.6 \pm 2.8$ & 0.0008 & 0.79 \\
& & $p=0.28$ & $p=0.01$ & $p=0.0003$ & & \\
03:00-06:00 & 6.3 & $(2.1)$ & $-21.5 \pm 14.3$ & $18.8 \pm 6.7$ & 0.0004 & 0.82 \\
& & $p=0.75$ & $p=0.008$ & $p=0.0001$ & & \\
06:00-09:00 & 2.5 & $(1.3)$ & $-4.2 \pm 1.9$ & $4.6 \pm 1.1$ & 0.00002 & 0.91 \\
& & $p=0.1$ & $p=0.0009$ & $p=0.0000$ & & \\
09:00-12:00 & 1.2 & $2.5 \pm 2.3$ & $(-2.0)$ & $4.0 \pm 1.5$ & 0.0006 & 0.80 \\
& & $p=0.03$ & $p=0.09$ & $p=0.0002$ & & \\
12:00-15:00 & 3.2 & $(4.3)$ & $(-4.8)$ & $2.4 \pm 1.9$ & 0.02 & 0.43 \\
& & $p=0.06$ & $p=0.06$ & $p=0.02$ & & \\
15:00-18:00 & 1.6 & $(7.1)$ & $-2.2 \pm 2.0$ & $1.9 \pm 1.2$ & 0.02 & 0.60 \\
& & $p=0.41$ & $p=0.03$ & $p=0.005$ & & \\
18:00-21:00 & \multirow{2}{*}{1.1} & $(1.1)$ & $(-1.3)$ & $0.7 \pm 0.6$ & 0.02 & 0.45 \\
21:00-24:00 & 2.6 & $p=0.12$ & $p=0.08$ & $p=0.02$ & & \\
& \multirow{2}{*}{2.9} & $(2.9)$ & $(-4.2)$ & $2.8 \pm 1.7$ & 0.005 & 0.56 \\
00:00-24:00 & 7.0 & $(5.8)$ & $-16.7 \pm 8.9$ & $1.8 \pm 0.6$ & 0.0001 & 0.86 \\
& & $p=0.14$ & $p=0.003$ & $p=0.0000$ & & \\
\hline
\end{tabular}

their data set suffers the disadvantage that two quite different radars were used before and after 1998, introducing considerable uncertainty in the relative calibration. Also, the pvalue of their result for the dependence of OR on solar activity (>0.1) was lower than the present result for $\eta(\sim 0.003)$. (Both estimates based on the same Fisher F-test.)

\section{Discussion}

\subsection{PMSE volume reflectivity and solar flux}

Variations of solar flux can influence PMSE strength in at least three different ways: via changing ionization, the amount of water vapour and the atmospheric temperature in the upper mesosphere and lower thermosphere region.

Electron density in this region is mainly determined by NO ionization by the solar Lyman $\alpha$ flux which is expected to vary in the same way as the solar $10.7 \mathrm{~cm}$ radio flux, with values ranging from 3.5 to $5.5 \times 10^{11}$ photons $\mathrm{cm}^{-2} \mathrm{~s}^{-1}$, between minimum and maximum solar activity during the interval from 1997 to 2009 (Woods, 2008, see also Fig. 7 in Bremer et al., 2006). An increase in solar Lyman $\alpha$ radiation leads to increased water vapour photo-dissociation (Brasseur and Solomon, 1986). This should result in less ice-particle formation (von Zahn et al., 2004) and hence should affect
PMSE. Variation of solar radiation could also influence atmospheric temperature via production of ozone after photodissociation of $\mathrm{O}_{2}$ (Robert et al., 2010) and via changing atmospheric dynamics.

Kirkwood et al. (2010b) have found an empirical relation between PMSE $\eta$ and ionospheric plasma and ice particle parameters using the $54 \mathrm{MHz}$ radar MARA at Wasa, Antarctica and the SOFIE instrument onboard the AIM satellite. Radar volume reflectivity was found to be proportional to the product of background electron density and ice mass density. The result was based on PMSE observations during one season (for a time interval close to local midnight) and restricted to geomagnetically quiet conditions with $A p<15$, when there was no correlation between PMSE $\eta$ and Ap. If we apply this empirical relation, then for increased solar flux the enhanced electron density will counteract the decrease of ice mass due to depletion of water vapour and increased temperature. The net effect on $\eta$ depends on which factor prevails. Thus $\eta$ might either correlate or anti-correlate with solar flux. From our regression (Table 2) we can conclude that the net effect is negative. Similarly, anti-correlations with the solar cycle were found for both polar mesospheric cloud (PMC) albedo and occurrence (with 0.5-1 year shift) using satelliteborne observations covering 27 years (DeLand et al., 2007; Shettle et al., 2009). NLC occurrences from ground-based 
Table 3. Correlation coefficients.

\begin{tabular}{|c|c|c|c|c|}
\hline $\begin{array}{c}\text { Time, UT } \\
\mathrm{UT}=\mathrm{SLT}-1.5 \mathrm{~h}\end{array}$ & $\operatorname{Corr}(\eta, K)$ & Time, UT* & $\operatorname{Corr}(\delta H, A)^{*}$ & $\operatorname{Corr}\left(\delta H, V_{i}\right)^{*}$ \\
\hline 00:00-03:00 & $\begin{array}{c}0.76 \\
p=0.005\end{array}$ & 00:30-03:30 & 0.65 & 0.52 \\
\hline 03:00-06:00 & $\begin{array}{c}0.77 \\
p=0.004\end{array}$ & $03: 30-06: 30$ & 0.50 & 0.27 \\
\hline 06:00-09:00 & $\begin{array}{c}0.82 \\
p=0.001\end{array}$ & 06:30-09:30 & 0.08 & 0.56 \\
\hline 09:00-12:00 & $\begin{array}{c}0.82 \\
p=0.001\end{array}$ & $09: 30-12: 30$ & 0.17 & 0.90 \\
\hline $12: 00-15: 00$ & $\begin{array}{c}0.66 \\
p=0.02\end{array}$ & $12: 30-15: 30$ & 0.09 & 0.72 \\
\hline $15: 00-18: 00$ & $\begin{array}{c}0.59 \\
p=0.04\end{array}$ & $15: 30-18: 30$ & 0.30 & 0.59 \\
\hline $18: 00-21: 00$ & $\begin{array}{c}0.67 \\
p=0.02\end{array}$ & $18: 30-21: 30$ & 0.69 & 0.28 \\
\hline $21: 00-24: 00$ & $\begin{array}{c}0.75 \\
p=0.004\end{array}$ & $21: 30-00: 30$ & 0.76 & 0.38 \\
\hline
\end{tabular}

* Correlation coefficients were adopted from Fig. 6a of Kellerman et al. (2009) and UT time was recalculated from magnetic local time (MLT) time for Kiruna as UT = MLT $-2.5 \mathrm{~h}$. $p$ is probability that there is no correlation between $\eta$ and $\mathrm{K}$-index.

visual observations also show a strong anticorrelation with solar flux (with a 1-year shift) as shown in the analysis of a 43-year dataset by Kirkwood et al. (2008).

\subsection{PMSE volume reflectivity and geomagnetic activity}

The K-index quantifies the disturbances in the horizontal component of the geomagnetic field measured on the ground. These disturbances are caused by those in ionospheric electrojet currents which depend on both conductance (heightintegrated conductivity) and hence electron density, and ionospheric electric field. Kellerman et al. (2009) showed that effect of conductance prevails during night-time and that of electric field dominates during daytime. In Table 3 we present correlation coefficients between $\eta$ and $\mathrm{K}$-index for each 3-h time interval together with probability $(p)$ that there is no correlation between them. We add to this table the results from Fig. 6 of Kellerman et al. (2009) for the correlation between perturbations in the horizontal component of the geomagnetic field $(\delta H)$, which is the basis of the K-index, cosmic noise absorption $(A)$ representing conductance due to energetic particle precipitation, and ion convection velocity $\left(V_{\mathrm{i}}\right)$ as a proxy for ionospheric electric field. From 18:00 UT to 06:00 UT, when the correlation between $\delta H$ and $A$ is high $(>0.5)$, it is reasonable to suggest that electron density variations due to energetic particle precipitations may be the cause of those in PMSE $\eta$. In the daytime (06:00 UT-15:00 UT) the electric field contributes most to K-index perturbations and hence perhaps also to those for $\eta$. The mechanism of such an influence is not obvious although vertical transport, as for metallic-ion sporadic-E layers might be involved (see e.g. Kirkwood and Nilsson, 2000). This possibility needs to be studied further.

Varney et al. (2010) derived a new analytical expression for PMSE $\eta$. They showed that when the electron density is much smaller than the ice particle density then the reflectivity is controlled by the electron density $N_{\mathrm{e}}$. In the opposite limit of high background electron density, PMSE strength is controlled by ice density $N_{\mathrm{d}}$. Our result does not contradict that obtained by Varney et al. (2010) because the analytical expression for $\eta$ obtained there cannot be directly applied to the year-to-year $\eta$ variations shown in Fig. 4. One can use that formula for qualitative analysis for two extreme cases when $N_{\mathrm{e}} \ll N_{\mathrm{d}}$ or $N_{\mathrm{e}} \gg N_{\mathrm{d}}$. Hervig et al. (2009) reported that the average $N_{\mathrm{d}}$ is $2-6 \times 10^{8} \mathrm{~m}^{-3}$ but can reach $10^{9} \mathrm{~m}^{-3}$. Electron densities at $80-90 \mathrm{~km}$ altitudes over Kiruna in summer time are determined by ionization by solar UV flux and by energetic magnetospheric particles which, in turn, vary with geomagnetic activity (Codrescu et al., 1997). For nighttime and geomagnetically quiet conditions $N_{\mathrm{e}}$ can be below $10^{9} \mathrm{~m}^{-3}$, however, for disturbed conditions electron density can exceed $10^{11} \mathrm{~m}^{-3}$ (Kirkwood and Collis, 1991). When calculating $\eta$ year-to-year variations we have averaged data over 2 months where there are days with strong (K-index $>5)$, moderate and weak $(\mathrm{K}$-index $=1)$ geomagnetic activity. 
Thus we averaged $\eta$ when electron density was high and low which makes the formula for $\eta$ by Varney et al. (2010) inapplicable for our result.

\subsection{Long-term trend}

For one 3-h interval (09:00-12:00 UT), a statistically significant positive trend of $2.5 \times 10^{-15} \mathrm{~m}^{-1}$ year $^{-1}$ was found. This gives an increase of PMSE volume reflectivities by $3.3 \times 10^{-14} \mathrm{~m}^{-1}$ over 13 years, which is comparable to the mean value of $\eta$ over this interval, $2.9 \times 10^{-14} \mathrm{~m}^{-1}$. However the regression coefficient for the variation of $\eta$ with the $\mathrm{K}$-index is $4 \times 10^{-13} \mathrm{~m}^{-1} / K$ and $K$ varies from a minimum value of 1.5 to a maximum value of 4 . Thus $\mathrm{K}$-index variations rather then a long-term trend primarily determine the behaviour of PMSE strength during the 13 years.

For daily averaged data we did not find any statistically significant trends in PMSE absolute strength during 19972009. As already mentioned in the introduction, we have a unique PMSE data set from which we were able to calculate seasonal means of PMSE $\eta$ including correction for changing antenna losses and transmitted power. We cannot compare our results with others since, to our knowledge, so far there is no such study regarding PMSE strength. However, there are a number of publications related either to PMSE occurrence rate (OR) or to NLC/PMC OR. Both Bremer et al. (2009) and Smirnova et al. (2010) did not find statistically significant trends in PMSE OR during 1994-2008 and 1997-2009, respectively. Similarly, Kirkwood et al. (2008) reported an absence of statistically confident trends in OR of moderate or bright NLCs over 43 years of observations. In contrast, positive and significant trends of up to $20 \%$ in OR of PMCs have been found in observations by satelliteborne instruments over the last 27 years (Shettle et al., 2009). This is too small to be visible on the shorter interval of 1315 years of PMSE observations and on the background of the large inter-annual variability. Moreover, PMSE OR is a complex quantity where trends/variations will depend on the interplay between those in water vapour and temperature (as for NLC/PMC) as well as in ionospheric conditions. Some studies showed indications of positive trends in the last 20 50 years in water vapour concentration (e.g. Lübken et al., 2009) and electron density below $90 \mathrm{~km}$ (e.g. Lastovicka and Bremer, 2004). Thus one could expect positive trends in PMSE strength and OR also. However, their values maybe not be large enough to be visible on an interval of just 13-15 years.

\section{Summary and outlook}

We have calculated the radar volume reflectivities for PMSE observed over Esrange, Northern Sweden during summers 1997-2009.
For the first time we have presented a new independent calibration method which allows estimation of the possible losses in antenna feed (and transmitter power) over the years and improves the accuracy of calculations for radar volume reflectivity.

The distribution of $\eta$ over magnitudes (histogram) varies from year to year with distribution maximum (peak of the histogram) lying in the range from $2 \times 10^{-15}$ to $3 \times$ $10^{-14} \mathrm{~m}^{-1}$.

Year-to-year variations of $\eta$ were found to be strongly correlated with the local geomagnetic K-index as averaged over $24 \mathrm{~h}$, and for every 3 -h interval. One possible explanations of the positive correlation is that increased geomagnetic activity can lead to enhanced ionization at altitudes $80-90 \mathrm{~km}$ and hence to enhanced $\eta$. There is also a hint that ionospheric electric field might influence PMSE strength, however this requires additional study.

In order to test the statistical significance of trend, solar cycle variation and geomagnetic activity in the year-toyear variability of PMSE strength, we have made a multiparameter linear fit to PMSE $\eta$, which includes all of these three factors. We found that both solar $10.7 \mathrm{~cm}$ flux and Kindex can explain $86 \%$ of inter-annual variations of $\eta$ averaged over $24 \mathrm{~h}$, where solar flux anti-correlates and K-index correlates with $\eta$. No statistically significant trends in PMSE yearly strengths were found over an interval of 13 years.

The conclusion regarding a possible relation between PMSE strength and ionospheric electric field discussed in Sect. 4.2 is not based on direct measurements of electric field and needs further study. This could be accomplished using e.g. the European incoherent scatter (EISCAT) VHF and UHF radars for simultaneous measurements of both quantities.

Acknowledgements. ESRAD radar is a joint venture between Swedish Space Corporation, Esrange and Swedish Institute of Space Physics. The work of Maria Smirnova was funded by The Swedish National Graduate School of Space Technology hosted by Luleå University of Technology. This work has otherwise been funded by the Swedish Research Council grant 621-2007-4812.

Topical Editor C. Jacobi thanks two anonymous referees for their help in evaluating this paper.

\section{References}

Brasseur, G. and Solomon, S.: Aeronomy of the Middle Atmosphere, D. Reidel Publishing Company, Dordrecht, 2nd edn., 1986.

Bremer, J., Hoffmann, P., Höffner, J., Latteck, R., Singer, W., Zecha, W., and Zeller, O.: Long-term changes of mesospheric summer echoes at polar and middle latitudes, J. Atmos. Solar Terr. Phys., 68, 1940-1951, 2006.

Bremer, J., Hoffmann, P., Höffner, J., Latteck, R., Singer, W., and Zecha, W.: Long-term changes of (polar) mesosphere summer echoes, J. Atmos. Solar Terr. Phys., 71, 1571-1576, 2009. 
Chilson, P., Kirkwood, S., and Nilsson, A.: The Esrange MST radar: a brief introduction and procedure for range validation using balloon, Radio Sci., 34(2), 427-436, 1999.

Codrescu, M. V., Fuller-Rowell, T. J., Robie, R. G., and Evans, D. S.: Medium energy particle precipitation influences on the mesosphere and lower thermosphere, J. Geophys. Res., 102(A9), 19977-19987, 1997.

DeLand, M. T., Shettle, E. P., Thomas, G. E., and Olivero, J. J.: Solar backscattered ultraviolet (SBUV) observations of polar mesospheric clouds (PMCs) over two solar cycles, J. Geophys. Res., 108, 8445, doi:10.1029/2002JD002398, 2003.

DeLand, M. T., Shettle, E. P., Thomas, G. E., and Olivero, J. J.: Latitude-dependent long-term variations in polar mesospheric clouds from SBUV version 3 PMC data, J. Geophys. Res., 112, D10315, doi:10.1029/2006JD007857, 2007.

Gage, K. S.: Radar observations of the free atmosphere: Structure and dynamics, Radar in Meteorology, D. Atlas, Ed., Amer. Meteor. Soc., 534-574, 1990.

Gumbel, J., Stegman, J., Murtagh, D. P., and Witt, G.: Scattering phase functions and particle sizes in noctilucent clouds, Geophys. Res. Lett., 28, 1415-1418, 2001.

Hervig, M., Thompson, R., McHugh, M., Gordley, L., Russell III, J., and Summers, M.: First confirmation that water ice the primary component of polar mesospheric clouds, Geophys. Res. Lett., 28, 971-974, 2001.

Hervig, M. E., Gordley, L. L., Russell III, J. M., and Bailey, S. M.: SOFIE PMC observations during the northern summer of 2007, J. Atmos. Sol. Terr. Phys., 71(3-4), 331-339, doi:10.1016/j.jastp.2008.08.010, 2009.

Kellerman, A. C., Makarevich, R. A., Honary, F., and Hansen, T. L.: On the relationship between auroral absorption, electrojet currents and plasma convection, Ann. Geophys., 27, 473-486, doi:10.5194/angeo-27-473-2009, 2009.

Kirkwood, S. and Collis, P. N.: The high latitude lower ionosphere observed by EISCAT, Adv. Space Res., 10, 10109-10112, 1991.

Kirkwood, S., and Nilsson, H.: High-latitude sporadic-E and other thin layers - the role of magnetospheric electric fields, Space Sci. Rev., 91(3/4), 579-613, 2000.

Kirkwood, S., Belova, E., Dalin, P., Nilsson, H., Mikhaylova, D., and Wolf, I.: Polar mesosphere summer echoes at Wasa, Antarctica $\left(73^{\circ} \mathrm{S}\right)$ : first observations and comparison with $68^{\circ} \mathrm{N}$, Geophys. Res. Lett., 34, L15803, doi:10.1029/2007GL030516, 2007.

Kirkwood, S., Dalin, P., and Réchou, A.: Noctilucent clouds observed from the UK and Denmark - trends and variations over 43 years, Ann. Geophys., 26, 1243-1254, doi:10.5194/angeo-261243-2008, 2008.

Kirkwood, S., Belova, E., Satheesan, K., Narayana Rao, T., Rajendra Prasad, T., and Satheesh Kumar, S.: Fresnel scatter revisited - comparison of $50 \mathrm{MHz}$ radar and radiosondes in the Arctic, the Tropics and Antarctica, Ann. Geophys., 28, 1993-2005, doi:10.5194/angeo-28-1993-2010, 2010a.

Kirkwood, S., Hervig, M., Belova, E., and Osepian, A.: Quantitative relation between PMSE and ice mass density, Ann. Geophys., 28, 1333-1343, doi:10.5194/angeo-28-1333-2010, $2010 \mathrm{~b}$.
Lastovicka, J. and Bremer, J.: An overview of long-term trends in the lower ionosphere below $120 \mathrm{~km}$, Surv. Geophys., 25, 66-99, 2004.

Latteck, R., Singer, W., Morris, R. J., Holdsworth, D. A., and Murphy, D. J.: Observations of polar mesosphere summer echoes with calibrated VHF radars at $69^{\circ}$ in the Northern and Southern hemispheres, Geophys. Res. Lett., 34, L14805, doi:10.1029/2007GL030032, 2007.

Latteck, R., Singer, W., Morris, R. J., Hocking, W. K., Murphy, D. J., Holdsworth, D. A., and Swarnalingam, N.: Similarities and differences in polar mesosphere summer echoes observed in the Arctic and Antarctica, Ann. Geophys., 26, 2795-2806, doi:10.5194/angeo-26-2795-2008, 2008

Lübken, F.-J., Rapp, M., and Strelnikova, I.: The sensitivity of mesospheric ice layers to atmospheric background temperatures and water vapor, Adv. Space Res., 40, 794-801, 2007.

Lübken, F.-J., Berger, U., and Baumgarten, G.: Stratospheric and solar cycle effects on long-term variability of mesospheric ice clouds, J. Geophys. Res., 114, D00I06, doi:10.1029/2009JD012377, 2009.

Rapp, M. and Lübken, F.-J.: Polar mesosphere summer echoes (PMSE): Review of observations and current understanding, Atmos. Chem. Phys., 4, 2601-2633, doi:10.5194/acp-4-2601-2004, 2004.

Robert, C. E., von Savigny, C., Rahpoe, N., Bovensmann, H., Burrows, J. P., DeLand, M. T., and Schwartz, M. J.: First evidence of a 27 day solar signature in noctilucent cloud occurrence frequency, J. Geophys. Res., 115, D00I012, doi:10.1029/2009JD012359, 2010.

Shettle, E. P., DeLand, M. T., Thomas, G. E., and Olivero, J. J.: Long term variations in the frequency of polar mesospheric clouds from SBUV, Geophys. Res. Lett., 36, L02803, doi:10.1029/2008GL036048, 2009.

Smirnova, M., Belova, E., Kirkwood, S., and Mitchell, N.: Polar mesosphere summer echoes with ESRAD, Kiruna, Sweden: variations and trends over 1997-2008, J. Atmos. Solar Terr. Phys., $72,435-447,2010$.

Swarnalingam, N., Hocking, W. K., and Argall, P. S.: Radar efficiency and the calculation of decade-long PMSE backscatter cross-section for the Resolute Bay VHF radar, Ann. Geophys., 27, 1643-1656, doi:10.5194/angeo-27-1643-2009, 2009.

Thomas, G. E. and Olivero, J.: Noctilucent clouds as possible indicators of global change in the mesosphere, Adv. Space Res., 28 , 937-946, 2001.

Varney, R. H., Kelley, M. C., Nicolls, M. J., Heinselman, C. J., and Collins, R. L.: The electron density dependence of polar mesospheric summer echoes. J. Atmos. Solar Terr. Phys., in press, doi:10.1016/j.jastp.2010.07.020, 2010.

von Zahn, U., Baumgarten, G., Berger, U., Fiedler, J., and Hartogh, P.: Noctilucent clouds and the mesospheric water vapour: the past decade, Atmos. Chem. Phys., 4, 2449-2464, doi:10.5194/acp-4-2449-2004, 2004.

Woods, T.: Composite Lyman Alpha, http://lasp.colorado.edu/ lisird/lya/, 2008. 